УДК 331.45:620.9

ОСОБЕННОСТИ ОРГАНИЗАЦИИ ОХРАНЫ ТРУДА

В СФЕРЕ ЭНЕРГЕТИКИ

\title{
LABOR PROTECTION ORGANIZATION FEATURES \\ IN THE ENERGY SPHERE
}

\author{
Вадулина Н.В., Юсупова Л.Р., Киреев Б.А., \\ Хайруллина 3.Д., Салимов А.О.
}

Уфимский государственный нефтяной технический университет, г. Уфа, Российская Федерация

\author{
N.V. Vadulina, L.R. Yusupova, B.A. Kireyev, \\ Z.D. Khayrullina, A.O. Salimov
}
Ufa State Petroleum Technological University, Ufa, Russian Federation

\section{e-mail: liana_yusupova_2017@mail.ru}

\begin{abstract}
Аннотация. Риск и опасность в сфере электроэнергетики неизбежны, они являются ее составной частью. Для работников, работающих в сфере электроэнергетики, труд связан с высокой вредностью производства и большими нагрузками. По вредности производства их труд стоит на третьем месте среди отраслей российской промышленности.

В данной статье определены основные травмоопасные виды экономической деятельности в сфере энергетики - это производство, передача и распределение электроэнергии. По данным последних 3-4 лет, такой вид деятельности, как производство, входит в первую шестерку отраслей экономики по количеству погибших, и в нем отмечается наибольшее число несчастных случаев со смертельным исходом.
\end{abstract}


Определена потенциальная опасность для обслуживающего персонала. Наиболее характерный опасный производственный фактор для данной сферы - это электрический ток. Рассмотрены особенности электрического тока.

Определены требования к квалификации и подготовке электротехнического персонала и государственных инспекторов, осуществляющих надзор, а также специалистов по охране труда, контролирующих работу электроустановок.

Также определены особенности проведения надзорных мероприятий в сфере энергетики, которые исходят из особенностей организации охраны труда в сфере энергетики.

Указаны особенности работы с персоналом на предприятии, а также приведены порядки допуска к самостоятельной работе работников рабочих профессий ремонтного персонала, оперативного и ремонтно-оперативного персоналов.

Определены порядок проверки допуска строительно-монтажных организаций и организация их безопасной работы. Изложены пункты, которые проверяются при оценке организации работ в электроустановках.

Abstract. The risk and danger in the electric power industry are inevitable, they are its integral part. For workers working in the electric power industry, labor is associated with high production hazards and high loads. For the harmfulness of production, their work is in third place among the branches of Russian industry.

This article identifies the main traumatic economic activities in the energy sector - the production, transmission and distribution of electricity. According to the data of the last 3-4 years, this type of activity, such as production, is among the top six sectors of the economy in terms of the number of people killed, and it has the largest number of fatal accidents. 
Potential danger to attendants has been identified. The most characteristic dangerous production factor for this area is electric current. Considered features of the electric current.

Requirements for the qualification and training of electrical personnel and state inspectors exercising supervision, as well as specialists in labor protection who control the work of electrical installations have been determined.

It also identified the features of the oversight activities in the energy sector, which are based on the characteristics of the organization of labor protection in the energy sector.

The features of work with personnel at the enterprise are indicated, and the procedures for admission to the independent work of workers in the professions of repair personnel, operational and repair and operational personnel are given.

Determined the procedure for checking the admission of construction and installation organizations and the organization of their safe operation. Set out the points that are checked when evaluating the organization of work in electrical installations.

Key words: electric power industry, labor protection organization, supervisory activities in the energy sector, electrotechnical personnel.

Ключевые слова: электроэнергетика, организация охраны труда, надзорные мероприятия в энергетике, электротехнический персонал.

Анализ производственного травматизма в Российской Федерации, который осуществляется Федеральной службой по труду и занятости, говорит нам о том, что к наиболее травмоопасным видам экономической деятельности можно отнести производство, передачу и распределение электроэнергии [1]. По данным последних 3-4 лет, такой вид деятельности, как производство, входит в первую шестерку отраслей экономики по количеству погибших, и в нем отмечается наибольшее число несчастных случаев со смертельным исходом. 
Потенциальную опасность для обслуживающего персонала представляет следующий опасный производственный фактор электрический ток. Его особенность состоит в том, что его нельзя ощутить органами чувств, то есть для предупреждения поражения электрическим током работнику необходимо применять средства индивидуальной защиты. При этом, если имеются особо опасные или неблагоприятные условия в отношении поражения работников электрическим током, которые требуют выполнение работ в электроустановках по организационно-распорядительным документам, работникам предоставляются специальные права на организацию и выполнение работ $[2,3]$.

При наличии нескольких основных вредных и опасных производственных факторов, сюда относится и факторы, не связанные с электрическим током, необходимо выполнить работы без применения средств подмащивания, выполняемые на высоте 5 м и более. Также на работу электрооборудования и на работников, обслуживающих электроустановки на открытом воздухе, влияют различные метеоусловия, такие как грозы, осадки, холод и жара, ветер и т.д. [4].

Поэтому для безопасной эксплуатации электроустановок работниками, начиная от непосредственных исполнителей и заканчивая руководителями, нужно соблюдать правила по охране труда. Безопасной считается работа, выполненная по правилам, прописанным в инструкциях по охране труда и в наряде-допуске. При этом немаловажную роль играют правильность и обязательность применения средств индивидуальной защиты, выдаваемых работникам, а также средств коллективной защиты, которыми должны быть укомплектованы электроустановки. Несоблюдение этих требований чревато травмами на производства $[5,6]$.

Электроустановки должны быть удалены друг от друга на значительное расстояние. Профессии и виды работ, к которым предъявляются дополнительные или повышенные требования, 
совмещаются. Эксплуатировать электроустановки может только подготовленный электротехнический персонал. Работа с персоналом является одним из основных направлений в деятельности энергетических организаций. Электротехнический персонал предприятий делится на следующие виды:

- административно-технический,

- оперативный,

- ремонтный,

- оперативно-ремонтный

с предоставлением соответствующих прав работы в электроустановках. Безопасной работа в электроустановках считается, если обеспечено выполнение организационных и технических мероприятий безопасного проведения работ в электроустановках.

Работа с персоналом в организациях электроэнергетики осуществляется в соответствии с требованиями «Правила работы с персоналом в организации электроэнергетики Российской Федерации», а в организациях, приобретающих электрическую энергию для собственных бытовых и производственных нужд - «Правила технической эксплуатации электроустановок потребителей» [7].

Рекомендованный порядок проверки допуска к самостоятельной работе работников рабочих профессий ремонтного персонала представлен на рисунке 1 , а оперативного и ремонтно-оперативного - на рисунке 2. 




Рисунок 1. Порядок допуска к самостоятельной работе работников рабочих профессий ремонтного персонала 


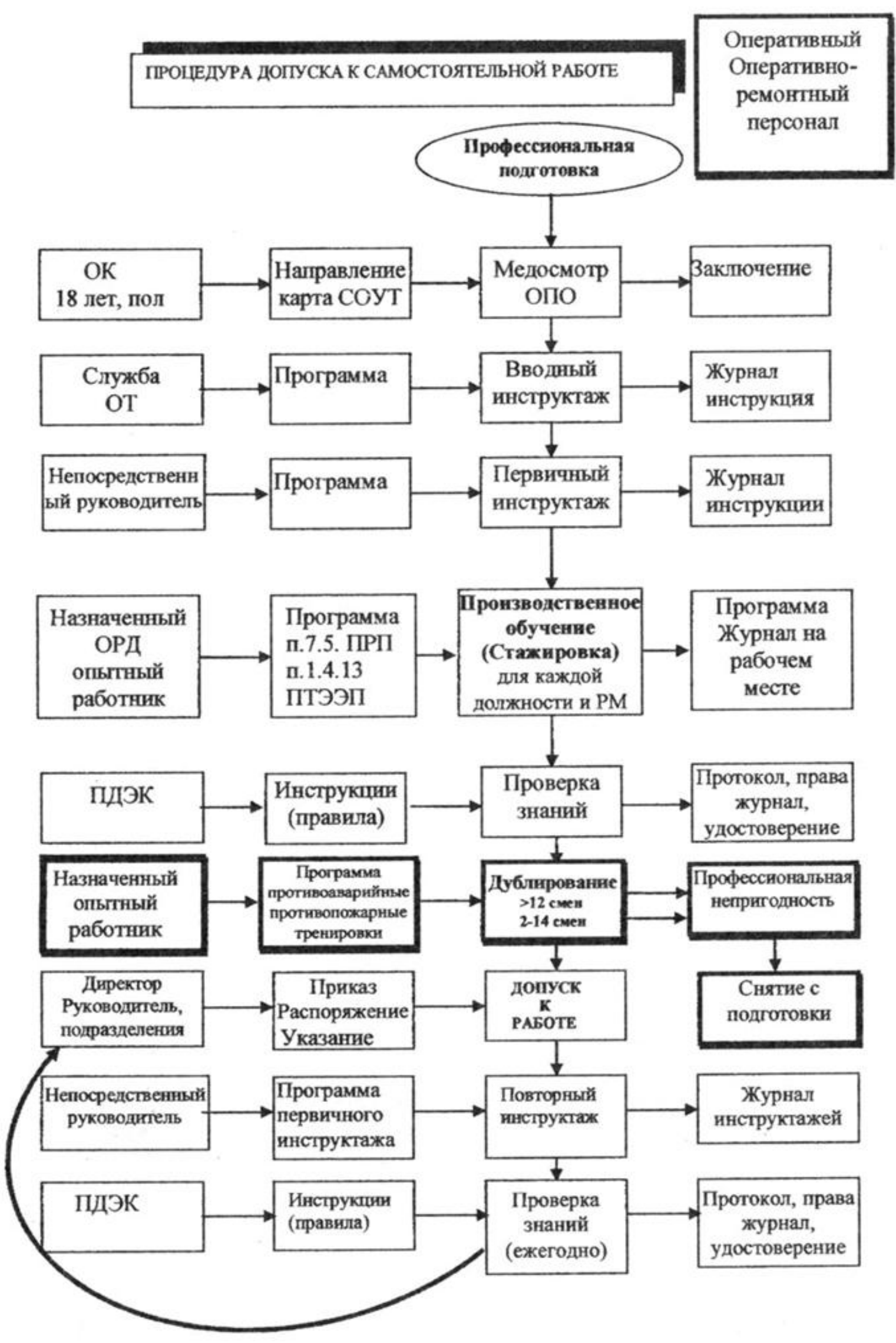

Рисунок 2. Порядок допуска к самостоятельной работе оперативного и ремонтно-оперативного персонала 
Технический надзор и контроль в пределах своей компетенции осуществляет Федеральная служба по экологическому, технологическому и атомному надзору. Государственные инспекторы, специалисты по охране труда, которые контролируют электроустановки, не являются электротехническим персоналом. Для них устанавливаются следующие требования: общий производственный стаж - не менее 3 лет, а также они могут иметь группу V.

При проведении надзорной деятельности государственные инспекторы должны проверить:

- наличие и ведение в организации организационнораспорядительных документов по охране труда при эксплуатации электроустановок;

- порядок проведения работы с электротехническим персоналом;

- порядок обучения, стажировки и проверки знаний по совмещаемым профессиям и видам работ, к которым предъявляются дополнительные требования по охране труда;

- порядок обучения по оказанию первой помощи пострадавшему на производстве, приемам освобождения пострадавшего от действия электрического тока с учетом специфики эксплуатируемых электроустановок;

- организационные мероприятия по обеспечению безопасного ведения работ в электроустановках;

- организацию медицинских осмотров;

- наличие на местах средств индивидуальной и коллективной защиты, сроки испытания защитных средств от поражения электрическим током, инструмента и приспособлений;

- порядок допуска строительно-монтажных организаций и организацию их безопасной работы.

При оценке организации работ в электроустановках проверяется соблюдение правил охраны труда при проведении работ на 
электротехническом оборудовании (нарядная система, подготовка рабочих мест, состояние заземления, комплектность и испытания защитных средств, инструмента и приспособлений). Также проверяется наличие документации по планово-предупредительным ремонтам или технологических карт. Проверяются наличие журналов учета нарядов и распоряжений, их ведение и правильность заполнения, правильность оформления и хранения нарядов, папки действующих и закрытых нарядов, соответствие их нормативным требованиям. Также проверяются наличие и состояние аптечек и сумок первой помощи, комплектность, наличие списков медикаментов и ответственного работника за пополнение аптечки; работы командированного персонала; наличие утвержденных инструкций и схем на рабочих местах, в организации согласно утвержденному перечню; наличие и выполнение графиков осмотров оборудования, профилактических испытаний и измерений; наличие графиков и выполнение планово-предупредительных ремонтов.

Важно помнить, что при проверках производственных объектов и рабочих мест должно уделяться особое внимание соблюдению требований правовых норм законодательных и иных нормативно-правовых актов, имеющих запретительный и ограничительный характер.

При оценке порядка допуска строительно-монтажных организаций и организации их безопасной работы рекомендуется следующий порядок самопроверки.

- Проверить наличие и содержание акта допуска на производство работ на территории действующего предприятия. Уделяется особое внимание наличию записи в акте-допуске или отдельном распоряжении организации - владельца электроустановок работников, имеющих допуск к работе работников СМО и право подписи наряда-допуска.

- В журналах регистрации инструктажей СМО и подразделения организации - владельца электроустановок проверить проведение вводного и первичного инструктажей по безопасности труда с указанием 
имеющихся на выделенном участке опасных факторов, изложенных в программе проведения инструктажа, инструкции по охране труда, наличие подписей работников СМО.

- Проверить содержание программы проведения первичного инструктажа с целью установления конкретных инструкций по охране труда, по которым проводился инструктаж.

- Проверить наличие и содержание наряда-допуска, выдаваемого ответственными работниками СMO по форме, установленной приложением № 2 к Правилам по охране труда в строительстве.

- Проверить наличие ограждения, препятствующего ошибочному проникновению персонала $\mathrm{CMO}$, должен выполнять допускающий, а работы в ней должны проводиться под надзором наблюдающего из числа персонала организации - владельца электроустановок.

- При проведение погрузочно-разгрузочной работы в охранной зоне линии электропередачи нужно проверять, есть ли письменное разрешение владельца линии электропередачи. Установка и работа кранов стрелового типа в охранной зоне линии электропередачи или на расстоянии менее 30 м от крайнего провода линии электропередачи осуществляются только по наряду-допуску в присутствии лица, ответственного за безопасное производство работ.

\section{Выводы}

В данной работе определены основные травмоопасные виды экономической деятельности в сфере энергетики - это производство, передача и распределение электроэнергии.

Определена потенциальная опасность для обслуживающего персонала. Определены требования к квалификации и подготовке электротехнического персонала и государственного инспектора, осуществляющий надзор, а так же специалиста по охране труда, контролирующий электроустановки, и особенности проведения надзорных 
мероприятий в сфере энергетики, которые исходят из особенностей организации охраны труда в сфере энергетики.

Соблюдение особенностей организации охраны труда хозяйствующих субъектов в сфере энергетики, рассмотренные в данной работе, помогает обеспечить безопасную эксплуатацию субъекта, что приводит к снижению показателей аварийности и как следствие снижает уровень смертности и травм на производстве.

\section{Список используемых источников}

1. Гайсина Л.М. Социальная устойчивость российских нефтегазовых компаний в условиях кризиса // Вестник Башкирского университета. 2011. T. 16. № 4. C. 1368-1371.

2. «Правила по охране труда при эксплуатации электроустановок», утвержденные приказом Министерства труда и социальной защиты Российской Федерации от 24.07.2013 № 328н, зарегистрированные Минюстом России 12 декабря 2013 г.

3. «Правила по охране труда при работе на высоте», утвержденные приказом Министерства труда и социальной защиты РФ от 28.03.2014 № 155н, зарегистрированные Минюстом России 5 сентября 2014 г.

4. Приказ Минтруда России от 17.06.2015 № 383н «О внесении изменений в Правила по охране труда при работе на высоте, утвержденные Приказом Министерства труда и социальной защиты РФ от 28 марта 2014 г. № 155 H».

5. Правила по охране труда в строительстве, утвержденные приказом Министерства труда и социальной защиты РФ 01.06 .2015 №336н. Зарегистрировано в Минюсте России 13.08.2015 № 38511.

6. «Правила технической эксплуатации электроустановок потребителей», утвержденные приказом Министерства Энергетики РФ от 13 января 2003 г. № 6, зарегистрированные Минюстом России 22 января 2003 г. Регистрационный № 4145. 
7. «Правила работы с персоналом в организациях электроэнергетики Российской Федерации», утвержденные приказом Минтопэнерго РФ от 19 февраля 2000 года № 49, зарегистрированные в Минюсте РФ 16 марта 2000 г. Регистрационный № 2150.

\section{References}

1. Gaysina L.M. Sotsial'naya ustoychivost' rossiyskikh neftegazovykh kompaniy $\mathrm{v}$ usloviyakh krizisa [Social stability of Russian oil and gas companies in a crisis]. Vestnik Bashkirskogo universiteta - Bulletin of the Bashkir University, 2011, Vol. 16, No. 4, pp. 1368-1371.

2. «Pravila po okhrane truda pri ekspluatatsii elektroustanovok», utverzhdennye prikazom Ministerstva truda i sotsial'noi zashchity Rossiiskoi Federatsii ot 24.07.2013 № 328n, zaregistrirovannye Minyustom Rossii 12 dekabrya 2013 g. [«Regulations on Labor Protection in the Operation of Electrical Installations», Approved by the Order of the Ministry of Labor and Social Protection of the Russian Federation dd. July 24, 2013 No. 328n, the Authority of the Ministry of Justice of Russia on December 12, 2013]. [in Russian].

3. «Pravila po okhrane truda pri rabote na vysote», utverzhdennye prikazom Ministerstva truda i sotsial'noi zashchity RF ot 28.03.2014 № 155n, zaregistrirovannye Minyustom Rossii 5 sentyabrya 2014 g. [«Regulations on Labor Protection in the Operation of Electrical installations», Approved by the Order of the Ministry of Labor and Social Protection of the Russian Federation dd. July 24, 2013 No. 328n, the Authority of the Ministry of Justice of Russia on December 12, 2013]. [in Russian]. 
4. Prikaz Mintruda Rossii ot 17.06.2015 № 383n «O vnesenii izmenenii v Pravila po okhrane truda pri rabote na vysote, utverzhdennye Prikazom Ministerstva truda i sotsial'noi zashchity RF ot 28 marta 2014 g. № 155n». [Order of the Ministry of Labor of Russia dd. 17.06.2015 No. 383n «On the Introduction of Changes to the Rules for Labor Protection when Working at Height, Approved by the Order of the Ministry of Labor and Social Protection of the Russian Federation dd. March 28, 2014. No. 155n»]. [in Russian].

5. Pravila po okhrane truda $v$ stroitel'stve, utverzhdennye prikazom Ministerstva truda $i$ sotsial'noi zashchity $R F \quad 01.06 .2015$ № 336n. Zaregistrirovano v Minyuste Rossii 13.08.2015 № 38511. [«Regulations on Labor Protection in Construction», Approved by the Order of the Ministry of Labor and Social Protection of the Russian Federation dd. 01.06.2015 No. 336n. Registered in the Ministry of Justice of Russia dd. 13.08.2015 No. 38511]. [in Russian].

6. «Pravila tekhnicheskoi ekspluatatsii elektroustanovok potrebitelei», utverzhdennye prikazom Ministerstva Energetiki RF ot 13 yanvarya 2003 g. № 6, zaregistrirovannye Minyustom Rossii 22 yanvarya 2003 g. Registratsionnyi № 4145. [«Regulations on the Technical Operation of Consumer Electrical Installations», Approved by Order No. 6 of the Ministry of Energy of the Russian Federation dd. January 13, 2003 Registered by the Ministry of Justice of Russia dd. January 22, 2003, Registration No. 4145]. [in Russian].

7. «Pravila raboty $s$ personalom $v$ organizatsiyakh elektroenergetiki Rossiiskoi Federatsii», utverzhdennye prikazom Mintopenergo RF ot 19 fevralya 2000 goda № 49, zaregistrirovannye v Minyuste RF 16 marta 2000 g. Registratsionnyi № 2150. [«Regulations on Work with Personnel in the Organizations of the Electric Power Industry of the Russian Federation», Approved by the Order of the Ministry of Fuel and Energy of the Russian Federation dd. February 19, 2000, No. 49, Registered with the Ministry of Justice of the Russian Federation dd. March 16, 2000. Registration No. 2150]. [in Russian]. 


\section{Сведения об авторах}

\section{About the authors}

Вадулина Н.В., канд. техн. наук, доцент кафедры «Промышленная безопасность и охрана труда», ФГБОУ ВО «УГНТУ», г. Уфа, Российская Федерация

N.V. Vadulina, candidate of Engineering sciences, assistant professor of industrial safety and labour protection department, FSBEI HE «USPTU», Ufa, Russian Federation

Юсупова Л.Р., студент гр. ББП-14-01, ФГБОУ ВО «УГНТУ», г. Уфа, Российская Федерация

L.R. Yusupova, Student of BBP-14-01 Group, FSBEI HE «USPTU», Ufa, Russian Federation

e-mail: liana_yusupova_2017@mail.ru

Киреев Б.А., студент гр. БГР-14-01, ФГБОУ ВО «УГНТУ», г. Уфа, Российская Федерация

B.A. Kireev, Student of BGR-14-01 Group, FSBEI HE «USPTU», Ufa, Russian Federation

Хайруллина 3.Д., студент гр. ББП-14-01, ФГБОУ ВО «УГНТУ», г. Уфа, Российская Федерация

Z.D. Khairulina, Student of BBP-14-01 Group, FSBEI HE «USPTU», Ufa, Russian Federation

Салимов А.О., студент гр. БАЭ-16-01, ФГБОУ ВО «УГНТУ», г. Уфа, Российская Федерация

A.O. Salimov, Student of BAE-16-01 Group, FSBEI HE «USPTU», Ufa, Russian Federation 